\title{
IRREGULARIDADE NAS ÁREAS PÚBLICAS E ÁREAS INSTITUCIONAIS - MICRORREGIÃO 15 DE PRESIDENTE PRUDENTE - SP
}

\author{
Jéssica Nunes Francoํㅜ, Marcos Norberto Boin², Mariane Gonçalves Olivo', Yeda Ruiz Maria ${ }^{1}$ \\ ${ }^{1}$ Universidade do Oeste Paulista - UNOESTE, curso de Arquitetura e Urbanismo, Presidente Prudente, SP. ${ }^{2}$ Universidade \\ Federal da Grande Dourados - UFGD, Dourados, MS. E-mail: yeda rm@hotmail.com
}

\section{RESUMO}

As cidades brasileiras vêm passando por um período de acelerada urbanização, que interfere diretamente na qualidade de vida de seus moradores. Com o intuito de organizar e planejar o crescimento urbano e assim garantir espaços para equipamentos urbanos essenciais à comunidade, são considerados comunitários os equipamentos públicos de educação, cultura, saúde, lazer e similares. Os espaços livres públicos não devem ser negligenciados, pois exercem papel funcional como de circulação urbana, social e cultural através do convívio público e ambiental na conservação e requalificação ambiental, sendo importantes elementos na infraestrutura das cidades. A partir de dezembro de 1979, através da Lei Federal № 6.766 foi definido como função dos municípios o controle de uso, ocupação e parcelamento do solo, além da garantia da existência dessas áreas livres na malha urbana. Na cidade de Presidente Prudente $\mathrm{SP}$, os bairros dispõem de área de lazer e institucional, porém muitas dessas áreas não seguem sua função original. Este artigo tem como finalidade identificar essas áreas na Microrregião 15.

Palavras-chave: Espaço público. Área Verde. Área de lazer. Área institucional. Microrregião 15. Presidente Prudente - SP.

\section{IRREGULARITY IN PUBLIC AREAS AND INSTITUTIONAL AREAS - MICROREGION 15 FROM PRESIDENTE PRUDENTE - SP}

\begin{abstract}
Brazilian cities are undergoing a period of rapid urbanization, which directly affects the quality of life of its residents. In order to organize and plan urban growth and thus ensure spaces for essential urban facilities to the community they are considered community public education equipment, culture, health, leisure and similar. The public free spaces should not be overlooked because exert functional role as the urban circulation, social and cultural through public and environmental interaction in conservation and environmental improvement, are important elements in the infrastructure of the cities. From December 1979 through the Federal Law No. 6766 has been set as a function of municipalities control of use, occupation and division of land, as well as ensuring the existence of these free spaces in the urban mesh. In the city of Presidente Prudente - SP, the neighborhoods have leisure area and institutional area, but many of these areas do not follow their original function. This article has as finality to identify those areas in Microregion 15.
\end{abstract}

Keywords: Public Space. Green area. Recreation area. Institutional area. Microregion 15. Presidente Prudente - SP. 


\section{INTRODUÇÃO}

O Parcelamento do Solo urbano (Lei no 6766/79) define que é responsabilidade do município o controlo do uso do solo.

Com o intuito de organizar e planejar o crescimento urbano e assim garantir espaços para equipamentos urbanos essenciais à comunidade, são considerados comunitários os equipamentos públicos de educação, cultura, saúde, lazer e similares (art. 4ํㅡ § 2ํ). Desta forma, áreas destinadas à implantação de equipamento urbano e comunitário, assim como as dos sistemas viários, com registro em Cartório, passam a integrar o domínio do município, na categoria de bens de uso comum do povo, tornando-se inalienáveis e imprescritíveis por natureza (art. 99, I e art. 100, do Código Civil).

A cidade de Presidente Prudente localiza-se no oeste do estado de São Paulo, próxima a divisa com os estados do Paraná e Mato Grosso do Sul. Fundada no ano de 1917, a cidade teve seu desenvolvimento inicial fomentado pela estrada de ferro Alta Sorocabana, em torno da qual a cidade se desenvolveu (LINS, 1982).

No ano de 1996 foi aprovado seu primeiro Plano Diretor que dispõe sobre o parcelamento do solo urbano da cidade, à luz da nova Constituição Federal Brasileira (1988), revisado em 2008 (Lei no 154/2008). Por esta lei, em seu artigo 12, fica estabelecido que os loteamentos "deverão atender, pelo menos, os seguintes requisitos:

I - as áreas públicas serão proporcionais à densidade de ocupação prevista para a gleba;

II - as áreas públicas, depois de descontadas as áreas de preservação, não serão inferiores a $35 \%$ (trinta e cinco por cento) da gleba total;

III - as áreas públicas compor-se-ão, no mínimo de:

a) áreas institucionais: 5\% (cinco por cento) a 10\% (dez por cento) da área loteável, a critério do órgão responsável pelo Planejamento do município, sendo isolada pelo Sistema Viário;

b) áreas de lazer: 10\% (dez por cento) a 15\% (quinze por cento) da área loteável;

c) sistema viário ou arruamento; mínimo $20 \%$ (vinte por cento) da área loteável;

d) áreas de preservação, quando for o caso;

e) áreas "NON AEDIFICANDI", quando for o caso.

São os diferentes tipos de usos da terra que definem áreas públicas. Corrêa (1995) aborda que esses usos definem a organização espacial da cidade, dessa forma setoriza o espaço urbano em centro comercial, áreas industriais, áreas residenciais, áreas de lazer, áreas de serviço e gestão, distinguindo em termos de forma e conteúdo social.

Para Loboda (2005) nas últimas décadas a preocupação quanto à problemas ambientais 
vem aumentando. Dessa forma, as áreas verdes tornaram-se os principais ícones de defesa do meio ambiente pela sua deterioração, e pelo exíguo espaço que lhes é destinado nos centros urbanos.

As cidades brasileiras vêm passando por um período de acelerada urbanização, que interfere diretamente na qualidade de vida de seus moradores. Logo, a falta de planejamento, que considere os elementos naturais, é uma problemática que vem se acentuando e que resulta em empobrecimento da paisagem, e diferentes problemas em virtude dos vários subsistemas que coexistem no espaço urbano.

Para Guzzo (1999) as três principais funções das áreas verdes são: ecológica, estética e social. As contribuições ecológicas ocorrem na medida em que os elementos naturais que compõem esses espaços minimizam tais impactos decorrentes da industrialização. A função estética se da, principalmente, no papel de integração entre os espaços construídos e os destinados à circulação. $A$ função social está diretamente relacionada à disponibilização de espaços para o lazer da população.

Cavalheiro (1992) salienta que os espaços livres públicos não devem ser negligenciados, pois exercem papel funcional como de circulação urbana, social e cultural através do convívio público e ambiental na conservação e requalificação ambiental, sendo importantes elementos na infraestrutura das cidades.

Neste sentido o presente artigo tem como objetivo aprofundar os conhecimentos a respeito das áreas livres públicas na Microrregião Administrativa ${ }^{1} 15$ da cidade de Presidente Prudente - SP, mapeando as áreas aprovadas legalmente como espaços livres - áreas institucionais, áreas de lazer, e verificando sua real utilização na atualidade e, desta forma, identificar possível incompatibilidade com a legislação federal, estadual e municipal.

A Microrregião 15 (fig. 01) está inserida na região periférica da cidade, a sul do quadrilátero central, e é composta por 14 (quatorze) bairros: Parque Alvorada, Vila Verinha, Vila Marina, Vila Mendes, Jardim Sumaré, Conjunto Habitacional José de Souza Reis, Jardim Marisa, Vila Rainho, Vila Centenário, Vila Áurea, Vila Luso, e três bairros Sem Denominação.

\footnotetext{
1 A divisão de Microrregião Administrativas foi uma maneira da Prefeitura Municipal subdividir a malha urbana de Presidente Prudente, não oficialmente, para possibilitar e facilitar os levantamentos da própria Prefeitura e do Ministério Público, relativas a falta de áreas públicas aprovadas legalmente e com usos alterados, conforme consta no Inquérito Civil - IC № MP : 14.0720.0000322/2.011-1. No total há 18 microrregiões.
} 


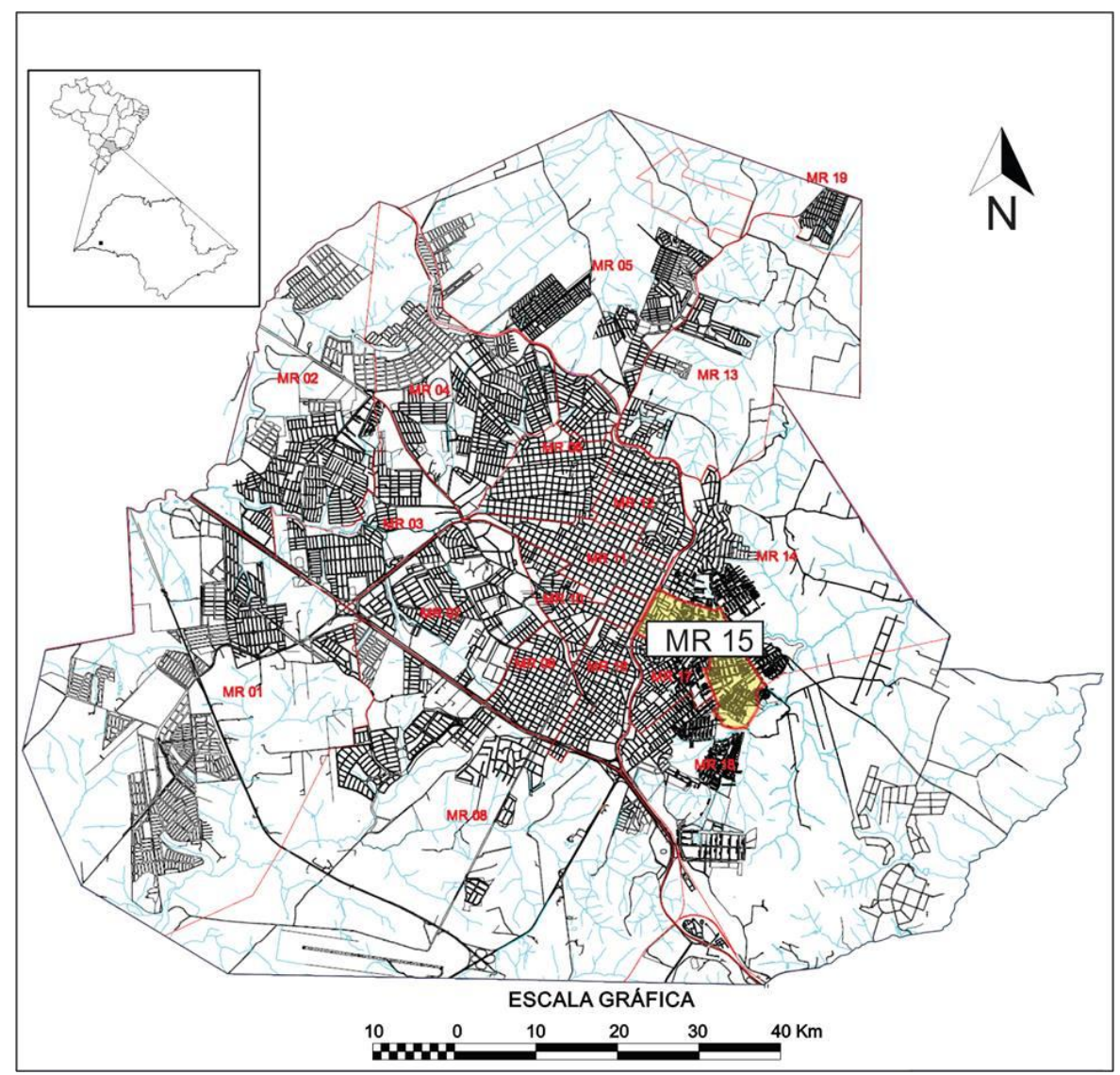

FIGURA 01: Mapa de Presidente Prudente, destacando a Microrregião 15.

Fonte: Autores, 2014.

Para tanto foram realizados levantamento bibliográfico, pesquisa documental, levantamentos físico-territoriais. A pesquisa bibliográfica foi em busca de compreender sobre áreas públicas, institucionais e outros assuntos pertinentes. Com a pesquisa documental buscou por políticas urbanísticas, ações voltadas às áreas públicas, institucionais, legislação Municipal, estadual e federal referente ao parcelamento, uso e ocupação do solo urbano, mapeamento dos bairros da microrregião 15. Também foram coletados dados como plantas de loteamentos, leis de zoneamento e decretos municipais, através do site da Prefeitura Municipal de Presidente Prudente -SP.

O levantamento físico territorial e a visita in loco tiveram o intuito de verificar aspectos físicos quanto à localização e a finalidade dos usos aos quais foram destinadas. Foram utilizadas técnicas de geoprocessamento e sensoriamento remoto, através do programa Spring 5.2.3, com imagens fotográficas aéreas e imagem de satélite do Google Earth, para assim mapear a microrregião 15. 


\section{2. ÁREAS PÚBLICAS E ÁREAS INSTITUCIONAIS - MICRORREGIÃO 15 DE PRESIDENTE PRUDENTE -} SP

Os quatorze bairros que compõem a microrregião 15 foram avaliados individualmente mediante a metodologia adotada, pela a qual foi identificado:

- Área que deveria ser de lazer sendo utilizada como terminal urbano.

- Área desapropriada para construção do sistema viário, porém uma parte não cumpre sua função.

- Áreas que constam estarem desocupadas na escritura, no entanto o local está ocupado por construções.

- Situações em que consta na escritura como sendo Área de Lazer, contudo deveria ser considerada Área de Preservação Permanente (APP).

- Várias áreas tanto de lazer como institucionais foram desapropriadas sendo destinadas a determinado uso, porém hoje se encontram desocupadas.

- Área que deveria ser de preservação permanente foi invadida por residências de um bairro vizinho.

- Áreas de lazer, verde e institucional foram desapropriadas pelo projeto de desfavelamento e se encontram loteadas.

\section{CONCLUSÃO}

Conforme observamos o maior erro encontrado esta na falta de controle e fiscalização das áreas publicas, fato este que não se limita apenas a essa área e sim à realidade do município de Presidente Prudente-SP. As áreas livres públicas e institucionais sofrem descaso quanto a sua devida importância social e ambiental, o que torna a situação consideravelmente preocupante. Não havendo estudo aprofundado das condições físicas e ambientais sendo destinado de acordo com o que é considerado viável no momento.

Com a desordem no crescimento da cidade e a deficiência do poder publico, áreas que deveriam ser preservadas são ignoradas e ocupadas de modo irregular. Foi verificado que algumas áreas foram desapropriadas para benfeitoria na cidade, mas posteriormente não cumpre com sua real destinação.

Devido à doação de muitas áreas publicas para loteamentos e inserção do sistema viário ocasionou em carência de espaços para mobiliários públicos, áreas educacionais e de lazer.

A maioria das áreas verdes e institucionais foram doadas para outros fins repercutindo em déficit de espaços interativos e infraestrutura para melhor atender a população, assim há 
necessidade de resgatá-las para sua real finalidade.

\section{REFERÊNCIAS}

BRASIL. Lei n.6.766, de 19 de dezembro de 1979. Dispõe sobre o parcelamento do solo urbano e dá outras providências.

BRASIL. Constituição da República Federativa do Brasil de 1988. Tem como fundamentos a soberania; a cidadania; a dignidade da pessoa humana; os valores sociais do trabalho e da livre iniciativa; o pluralismo político. Disponível em:< http:/www.trtsp.jus.br/legislacao/constituicaofederal-emendas>. Acesso em: 10 nov. 2014.

CAVALHEIRO, Felisberto; DEL PICCHIA, P. C. D. Áreas verdes: conceitos, objetivos e diretrizes para o planejamento. In: ENCONTRO NACIONAL SOBRE ARBORIZAÇÃO URBANA. Vitória-ES, de 13 a 18 de set/1992, Anais I e II, pp.29-38, 1992.

CORRÊA, L. R. O Espaço Urbano. Editora Ática. Série Princípios. 3a edição. №174, 1995.

GUZZO, P. Estudos dos espaços livres de uso público e da cobertura vegetal em área urbana da cidade de Ribeirão Preto-SP. 1999. 106f. Dissertação (Mestrado em Geociências). Instituto de Geociências e Ciências Exatas, Universidade Estadual Paulista, Rio Claro. 1999.

LINS.M.L.F. Presidente Prudente na revolução. Presidente Prudente, 1982.

LOBODA, C.R; DE ANGELIS, B.L.D. Áreas Verdes Públicas Urbanas: conceitos, usos e funções. Revista AMBIÊNCIA- Revista do Centro de Ciências Agrárias e Ambientais, Guarapuava, n. 01, 2005.

PRESIDENTE PRUDENTE. Lei complementar $\mathbf{n}$ 154/2008 de 10 de janeiro de 2008. Dispõe sobre a Lei de Parcelamento do Solo para Fins Urbanos e dá outras providências. Paço Municipal "Florivaldo Leal", Presidente Prudente, SP, 10 jan.2008. Disponível em: <http://presidenteprudente.sp.gov.br/site/documento.do?cod=614>. Acesso em: 08 set.2014 